Communication: Here we report for the first time on phosphorylation of cotton cellulose using baker's yeast hexokinase and phosphoryl donor adenosine-5'-triphosphate. An enzymatic assay was adopted for determination of the degree of phosphorylation of cellulose. This functional modification of cellulose resulted in improved colorability and flame resistance.

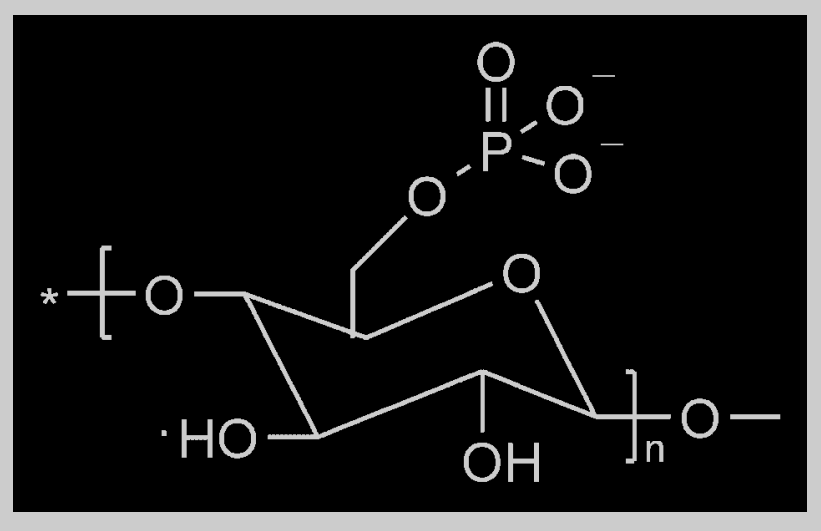

\title{
Phosphorylation of Cotton Cellulose with Baker's Yeast Hexokinase
}

\author{
Tzanko Tzanov, Maria Stamenova, Artur Cavaco-Paulo* \\ Departamento de Engenharia Têxtil, Universidade do Minho, Campus de Azurém, 4800-058 Guimarães, Portugal \\ Fax: +351253 510293; E-mail: artur@det.uminho.pt
}

Keywords: enzymes; hexokinases; functionalization of polymers

\section{Introduction}

The chemical modification of cotton cellulose, by introducing new functional groups or compounds, could be a way to improve dye fixation, water and soil-repellence, creaseresistance, handle, flame retardance and others. Hexokinase enzymes (EC 2.7.1.1.) catalyze phosphoryl transfer from adenosine- $5^{\prime}$-triphosphate (ATP) ${ }^{[1-4]}$ to the 6-hydroxyl group of a number of furanose and pyranose compounds. ${ }^{[5]}$ The ability of hexokinase to initiate the transfer of phosphate groups suggested the application of this enzyme to the functional modification of the C6-hydroxyl groups in cellulose. Chemical phosphorylation usually is a rather complicated process, requiring several protection and deprotection steps. ${ }^{[6,7]}$ Enzymatic phosphorylation can make the synthesis more efficient, eliminating many of these steps. The introduction of phosphate groups into cellulose will provide a polymer highly reactive toward various chemical compounds.

\section{Experimental Part}

Bleached, twill weave, $120 \mathrm{~g} \cdot \mathrm{m}^{-2}, 100 \%$ cotton fabric was used. The enzymatic phosphorylation of the samples was carried out at $30^{\circ} \mathrm{C}$ in an Ahiba Spectradye-Datacolor dyeing apparatus with closed vessels, at 40 r.p.m. for $6 \mathrm{~h}$, with $40 \mathrm{U} \cdot \mathrm{mL}^{-1}$ hexokinase (EC 2.7.1.1., Type IV: from baker's yeast, Sigma; one unit will phosphorylate $1 \mu \mathrm{mol}$ of D-glucose per min at $\mathrm{pH} 7.6$ at $25^{\circ} \mathrm{C}$ ) dissolved in $50 \mathrm{mmol}$ potassium phosphate buffer (pH 7.6) and $50 \mathrm{mmol}$ of a solution of ATP in deionized water, disodium salt (Sigma), using a liquor to fabric ratio of 20:1. Fabrics were first treated with the ATP solution for $15 \mathrm{~min}$ to ensure the impregnation of the textile material, and then the enzyme was added. After completing the process the enzymatically treated fabrics were washed under reflux to remove any residual protein.

Sigma procedure No. 345-UV for quantitative, ultraviolet, kinetic determination of glucose-6-phosphate dehydrogenase (G-6-PDH, EC 1.1.1.49) in blood at $340 \mathrm{~nm}$, was adopted for the detection of glucose-6-phosphate (G-6-P) formed in the hexokinase phosphorylation reaction. G-6-PDH is an enzyme that catalyzes the first step in the pentose phosphate shunt, oxidizing glucose-6-phosphate to 6-phosphogluconate (6-PG) and reducing nicotinamide adenine dinucleotide phosphate (NADP) to NADPH, according to Equation (1):

$$
\text { G-6-P }+\mathrm{NADP}^{+} \stackrel{\mathrm{G}-6-\mathrm{PDH}}{\longleftrightarrow} 6-\mathrm{PG}^{+} \mathrm{NADPH}+\mathrm{H}^{+}
$$

NADP is reduced by G-6-PDH in the presence of G-6-P. The rate of formation of NADPH (measured spectrophotometrically following the increase in absorbance at $340 \mathrm{~nm}$ ) is proportional to the G-6-PDH activity and thus to the 
concentration of G-6-P. The assay mixture contains $1 \mathrm{~mL}$ $\operatorname{NADP}\left(1.5 \mathrm{mmol} \cdot \mathrm{L}^{-1}\right)$ and $0.01 \mathrm{~mL} \mathrm{G}-6-\mathrm{PDH}\left(2 \mathrm{U} \cdot \mathrm{mL}^{-1}\right.$; one unit will oxidize $1.0 \mu \mathrm{mol}$ of $\mathrm{D}$-glucose 6-phosphate to 6-phospho-D-gluconate per min in the presence of NADP at $\mathrm{pH} 7.4$ at $\left.25^{\circ} \mathrm{C}\right)$. The solution was stored at room temperature $\left(18-26^{\circ} \mathrm{C}\right)$ for $5-10 \mathrm{~min}$. Then $2.0 \mathrm{~mL} \mathrm{G}-6-\mathrm{P}\left(1.05 \mathrm{mmol} \cdot \mathrm{L}^{-1}\right)$ were added and mixed gently. The absorbance of the sample (A) at $340 \mathrm{~nm}$ vs water was recorded as $A_{\mathrm{i}}$. The final absorbance $\left(A_{\mathrm{f}}\right)$ was recorded $5 \mathrm{~min}$ later. The G-6-PDH activity was defined as: $\Delta A \cdot \min ^{-1}=\left(A_{\mathrm{i}}-A_{\mathrm{f}}\right) / 5$. The standard curve of G-6-PDH activity as a function of G-6-P concentration was set $\left(Y=0.292 \times X, R^{2}=0.981\right)$ so that the concentration of a sample containing unknown amounts of G-6-P could be calculated. Then $1 \mathrm{~g}$ sample of phosphorylated cotton fabric was completely hydrolyzed to the constituting glucose and presumably glucose-6-phosphate units with $0.91 \mathrm{~g} \cdot \mathrm{L}^{-1}$ total crude cellulase Ecostone L (Röhm Enzyme, Finland), at $37^{\circ} \mathrm{C}$, $\mathrm{pH} 5$, for $24 \mathrm{~h}$. The solution was filtered through an Ultrafree-4 centrifugal filter unit for concentration and purification of biological samples (Millipore Corp.), in order to separate protein from sugars. The sample of G-6-P in the Sigma assay was replaced with equivalent amounts of enzymatically hydrolyzed, hexokinase-treated cellulose.

\section{Results and Discussion}

The spectrophotometrically detected activity of G-6-PDH toward the hydrolyzed cotton fabric treated with hexokinase is a clear evidence for the occurrence of enzymatic phosphorylation of cellulose. This enzymatic approach provides an alternative to the ${ }^{31} \mathrm{P}$ NMR or XPS techniques, since the degree of phosphorylation expected on the fabrics is rather low. The enzymatic procedure is reliable due to the high specificity of the enzyme toward the substrate under investigation. The concentration of G-6-P $\left(0.01986 \mathrm{~g} \cdot \mathrm{L}^{-1}\right)$ in the hydrolyzed cellulose was calculated according to a calibration curve. This value corresponds to a phosphorylation of $0.03 \%$ of the glucopyranose units. Phosphorylation occurs on the primary alcohol groups of cellulose, which are best available for reaction. The secondary 3-OH group forms extra hydrogen bonds with the ring oxygen atom, and the chain is additionally coiled, protecting the 2-OH groups. The expected reaction mechanism is shown in Scheme 1. Conventional dyeing procedures ${ }^{[8]}$ with basic, direct and reactive dyes resulted in an improvement of $10 \%$ in terms of dye fixation on hexokinase-treated cotton. The enzymatically phosphorylated fabrics showed nearly threefold retarded fire propagation ${ }^{[9]}\left(1.1 \mathrm{~cm}^{2} \cdot \mathrm{s}^{-1}\right)$, as compared to untreated cotton samples $\left(3 \mathrm{~cm}^{2} \cdot \mathrm{s}^{-1}\right)$, when exposed to flames.

\section{Conclusions}

This research reports on a new biosynthetic process for the phosphorylation of cotton cellulose with the enzyme hexokinase in the presence of phosphoryl donor ATP. The enzymatic procedure applied, originally developed for the determination of glucose-6-phosphate dehydrogenase, was sufficiently sensitive to detect the occurrence of phosphorylation, and represents an entirely innovative approach. Phosphorylation of $0.03 \%$ of the glucopyranose units in the cellulose provided a textile material with improved colorability and flame-resistance, which also might be used for a lot of chemical synthesis.

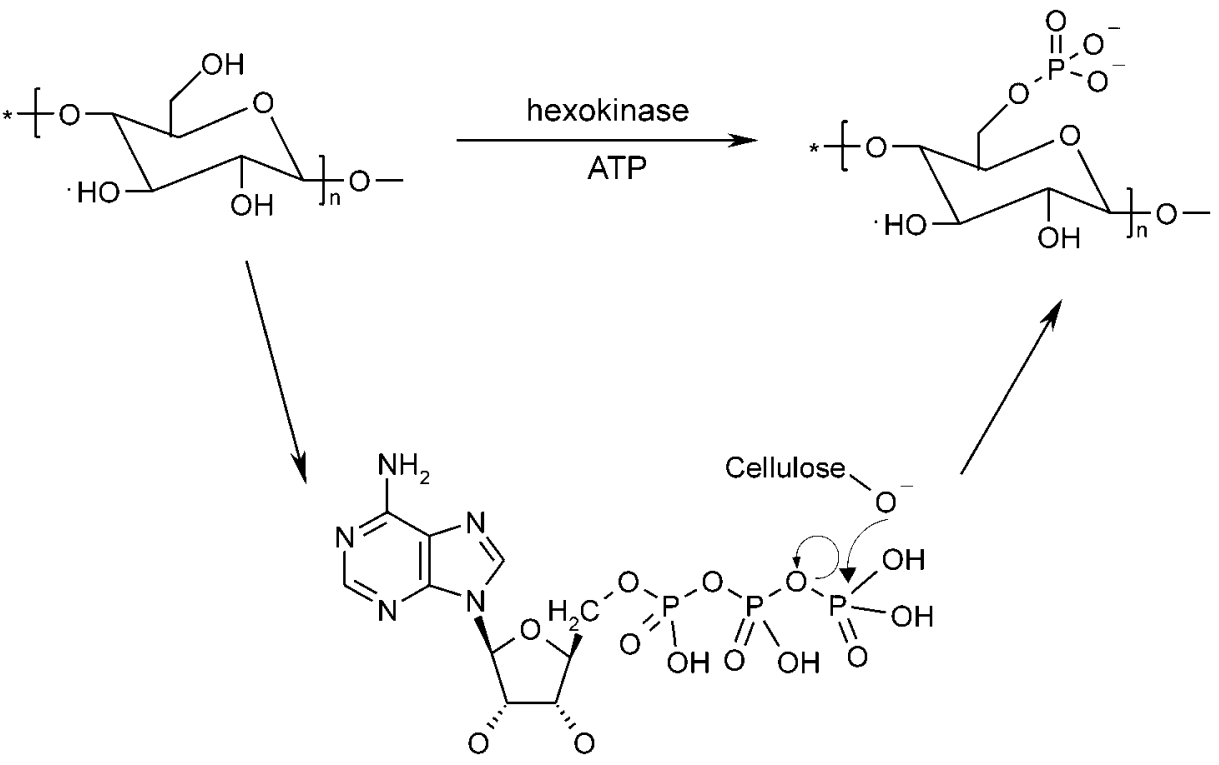

Scheme 1. Mechanism of hexokinase-catalyzed cellulose phosphorylation. 
Acknowledgement: We thank the HPMF-CT-2000-00868 project for providing a grant to Dr. Tzanov.

Received: September 18, 2002

Revised: October 22, 2002

Accepted: October 23, 2002

[1] H. K. Chenault, E. S. Simon, G. M. Whitesides, Biotechnol. Genet. Eng. Rev. 1988, 6, 221.

[2] G. M. Whitesides, C. H. Wong, Aldrichim. Acta 1983, 16, 27.

[3] G. M. Whitesides, C. H. Wong, A. Pollak, ACS Symp. Ser. 1982, 185, 205.
[4] C. Crans, R. J. Kazlauskas, B. L. Hirschbein, C. H. Wong, O. Abril, G. M. Whitesides, in: Methods Enzymol., Vol. 136, K. Mosbach, Ed., Academic Press Inc., New York 1987, p. 263.

[5] R. E. Viola, F. M. Raushel, A. L. Rendina, W. W. Cleland, Biochemistry 1982, 21, 1295.

[6] J. V. Edwards, D. R. Yager, I. K. Cohen, R. F. Diegelmann, S. Montante, N. Bertoniere, A. F. Bopp, Wound Repair Regen. 2001, 1,50 .

[7] S. S. Kim, W. Y. Jeong, B. C. Shin, S. Y. Oh, J. M. Rhee, J. Biomed. Mater. Res. 1998, 40, 401.

[8] C. H. Giles, "A Laboratory Course in Dyeing", The Society of Dyers and Colourists, Bragford, Yorkshire, England 1974, p. 65.

[9] Norme française NF G 07-184, Textiles-Comportement au feu, Méthode de classement en fonction de la surface brûlée, 1985. 